\title{
THE FREQUENCY DOMAIN CAUSALITY ANALYSIS BETWEEN ENERGY CONSUMPTION AND INCOME IN THE UNITED STATES
}

\author{
Aviral Kumar Timari *
}

\begin{abstract}
We investigated Granger-causality in the frequency domain between primary energy consumption/electricity consumption and GDP for the US by employing approach of Lemmens et al. (2008) and covering the period of January, 1973 to December, 2008. We found that causal and reverse causal relations between primary energy consumption and GDP and electricity consumption and GDP vary across frequencies. Our unique contribution in the existing literature lies in decomposing the causality on the basis of time horizons and demonstrating bidirectional the short-run, the medium-run and the long-run causality between GDP and primary energy consumption/electricity consumption and thus providing evidence for the feedback hypothesis. These results have important implications for the US for planning of the short, the medium and the long run energy and economic growth related policies.
\end{abstract}

Keywords: Energy consumption; Economic growth; Granger-causality in the frequency domain.

\section{Resumo}

Através do teste de casualidade de Granger, nós investigamos o domínio de frequência entre o consumo primário de energia/eletricidade e o produto interno bruto (PIB) dos Estados Unidos; aplicando a abordagem de Lemmens et al. (2008) e cobrindo o período entre Janeiro de 1973 a Dezembro de 2008. Nós achamos relações causal e causal reversa entre o consumo primário de energia e PIB, e o consumo de eletricidade e PIB variam através das frequências. Nossa contribuição única na literatura existente reside na decomposição da causalidade com base em horizontes de tempo e demonstração bi-direcional de causalidade de curto prazo, médio-prazo e longo-prazo entre PIB e consumo primário de energia/eletricidade e assim provendo evidência para a "feedback hypothesis". Estes resultados têm importantes implicações para o planejamento energértico de curto, médio e longo prazo dos Estados Unidos e políticas relacionadas ao crescimento econômico.

Palavras-chave: Consumo de Energia; Crescimento Econômico; GrangerCasualidade no Domínio da Frequência.

JEL classification: Q40, Q43, Q53, Q56.

DOI: http://dx.doi.org/10.1590/1413-8050/ea307

\footnotetext{
* Research scholar and Faculty of Applied Economics, Faculty of Management, ICFAI University Tripura. E-mail: aviral.eco@gmail.com
} 


\section{Introduction}

Voluminous studies have examined the relationship between energy consumption and economic growth and suggested policy implications derived from their empirical findings. This line of inquiry stems basically, from the earlier oil shocks of the 1970s to the more recent interest in energy prices and the impact of the Kyoto protocol agreement by a number of industrialized and developing countries to conserve energy and reduce greenhouse emissions in the face of achieving high growth rate of the economies. Economic theories, although, provide an unambiguous relationship between energy consumption, and economic growth (see section 2), the empirical investigation of the relationship between these variables has been one of the most attractive areas of energy economics literature for the last two decades. In recent years, there has been a renewed interest in examining the relationship between these variables. The high economic growth rates experienced by developing countries are achievable only with the consumption of a larger quantity of commercial energy, which is one of the key factors of production, though it leads to environmental degradation. There is still dispute on whether energy consumption is a stimulating factor for, or a result of, economic growth. In this we study reinvestigate the same issue but used a recent frequency domain approach developed by Lemmens et al. (2008), thus making a novel contribution to the research on the existing literature examining the relationship between energy consumption and economic growth. Our results have supported the findings of Yang (2000) for Taiwan, Zachariadis \& Pashourtidou (2007) for Cyprus, Tang (2008) and Lean \& Smyth (2010) for Malaysia, Aktas \& Yilmaz (2008) for Turkey, Odhiambo (2009a) for South Africa, Lorde et al. (2010) for Barbados, Ouédraogo (2010) for Burkina Faso, Tiwari (2010) for India and Shahbaz et al. (2011) for Portugal.

We focus on the United States (US) because of the important role that it plays in world energy markets. Soytas et al. (2007) make some observations regarding this. 'First, according to the Statistical Abstract of the US (2006), GHG emissions in the US rose nearly $17 \%$ between 1990 and 2000 before leveling off in 2001 and 2002. Second, over that same time period, the US accounted for around 23 to $24 \%$ of the world's total $\mathrm{CO}_{2}$ emissions from consumption of fossil fuels. Third, the US share of total world energy production has fallen slightly from $20 \%$ in 1990 to $18 \%$ and $17 \%$ in the years 2000 and 2003, respectively. Fourth, over the same time frame, the US share of total world energy consumption has remained fairly constant at around 24\%'. These facts confirm that the US is a significant consumer, as well as producer, of energy in the world economy. Therefore, it is important to better understand the relationships that exist between US economic growth and energy use before effective policies are developed.

The issue of the possible impact of $\mathrm{CO}_{2}$ emissions reduction on economic growth inevitably arises due to the possible connection between $\mathrm{CO}_{2}$ emissions and energy consumption, and energy consumption and economic growth. As a result of the importance of the possible connection between energy consumption and economic growth, literature is increasing in this area. In general, studies find evidence of correlation between these two variables for countries with different economic structures and different stages of economic development. The pioneering attempt in this area i.e., to study on the bidirectional relationship was made by Kraft and Kraft in 1978. They applied 
the Granger-causality (GC) test to US data for the period of 1947-1974, and found that a unidirectional causality runs from economic growth to energy consumption, thus suggesting that an energy conservation policy is feasible. Since Kraft \& Kraft (1978), there has been a vast body of studies contributing to this literature. Table 1 summarizes related studies.

Our observation from Table 1 indicates that studies in this area have produced mixed and often conflicting results for both developed and developing countries due to different methods, sample periods, and model specifications being employed. Furthermore, it is worth noting that most previous studies are limited in scope to the applications of linear models. However, economic events and regime changes such as changes in economic environment, in energy policy and fluctuations in energy price can cause structural alterations in the pattern of energy consumption for a given time period under study. This creates a room for a nonlinear rather than linear relationship between energy consumption and economic growth. Therefore, in the present study we made an attempt to analyze the issue in a nonlinear framework by using a recently developed nonparametric approach of Lemmens et al. (2008). Use of this approach allows us to decompose the GC in the frequency domain. In frequency domain, the key idea is that a stationary process can be described as a weighted sum of sinusoidal components with a certain frequency $\lambda$. As a result, one can analyze these frequency components separately. This analysis will make it possible to determine whether the predictive power is concentrated at the quickly fluctuating components or at the slowly fluctuating components. As such, instead of computing a single GC measure for the entire relationship, the GC is calculated for each individual frequency component separately. Thus, the strength and/or direction of the GC can be different for each frequency. In the present we study have considered two measures of energy consumption namely, primary energy consumption and electricity consumption. Two measures of energy consumption have been used to observe the robustness of our results. To the best of our knowledge, the analyses of GC from primary energy consumption and/or electricity consumption to economic growth and vice-versa have not yet been explored in the frequency domain. $^{1}$

The next section discusses the hypothesis data source and methodology. Section three presents empirical findings and section four draws conclusions and policy implications.

\section{Hypotheses, Data Source and Methodology}

The direction of causality between the energy consumption and economic growth has important policy implications as to whether an energy conser-

\footnotetext{
${ }^{1}$ It is important to mention that our analysis is based on the bivariate Granger causality analysis model and therefore, suffers from the problem of omitted variable bias. However, we would argue that even if this is the first case, to the best of our knowledge there is no such test developed which analyses nonlinear Granger-causality in a multivariate framework (the only exception negin is Breitung \& Candelon (2006) which can be applied for, at the most, a trivariate model. However, here we have preferred the test suggested by Lemmens et al. (2008) which is relatively more suitable vis-à-vis Breitung \& Candelon (2006) proposed test). Second, since the approach used in the study is based on a nonlinear framework, we would argue that if any omitted variable is able to transmit its effect on the measured variable and create nonlinearity in the data series, we are able to take care of the effect of those variables in our analysis through the approach we used.
} 
Table 1: Summary of Literature on Relationship between Electricity Consumption and Economic Growth

\begin{tabular}{|c|c|c|c|c|c|}
\hline Authors & Time Period & Methodology & Variables & Cointegration & Findings (country studied) \\
\hline \multicolumn{6}{|c|}{ Single-Country Studies } \\
\hline Yang (2000) & 1954-1997 & GC & Real GDP and Electricity Consumption & No & $\mathrm{EC} \leftrightarrow \mathrm{Y}$ (Taiwan) \\
\hline Ageel \& Butt (2001) & 1955-1996 & GC by Hsiao & Real GDP and Electricity Consumption & No & $\mathrm{EC} \rightarrow \mathrm{Y}($ Pakistan $)$ \\
\hline Ghosh (2002) & 1950-1997 & JML, GC & $\begin{array}{l}\text { Electricity Supply, Employment and Real } \\
\text { GDP }\end{array}$ & Yes & $\mathrm{ES} \leftarrow \mathrm{Y}($ India $)$ \\
\hline Jumbe (2004) & 1970-1999 & GC, & Real GDP and Electricity Consumption & Yes & $\mathrm{EC} \leftarrow \mathrm{Y}($ Malawi $)$ \\
\hline Shiu \& Lam (2004) & $1971-2000$ & JML, VECM & Real GDP and Electricity Consumption & Yes & $\mathrm{EC} \rightarrow \mathrm{Y}($ China $)$ \\
\hline Lee \& Chang (2005) & 1954-2003 & JML, VECM & $\begin{array}{l}\text { Real GDP per Capita and Electricity Con- } \\
\text { sumption per Capita }\end{array}$ & Yes & $\mathrm{EC} \rightarrow \mathrm{Y}($ Taiwan $)$ \\
\hline Narayan \& Smyth (2005) & 1966-1999 & ARDL, VECM & $\begin{array}{l}\text { Real GDP per Capita, Electricity Consump- } \\
\text { tion per Capita and Employment }\end{array}$ & Yes & $\mathrm{EC} \leftarrow \mathrm{Y}($ Australia $)$ \\
\hline Yoo (2005) & 1970-2002 & JML, VECM & Real GDP and Electricity Consumption & Yes & $\mathrm{EC} \rightarrow \mathrm{Y}($ Korea $)$ \\
\hline Yoo \& Kim (2006) & 1971-2002 & JML, GC by Hsiao & Real GDP and Electricity Supply & No & $\mathrm{ES} \leftarrow \mathrm{Y}($ Indonesia $)$ \\
\hline Ho \& Siu (2006) & 1966-2002 & JML, VECM & Real GDP and Electricity Consumption & Yes & $\mathrm{EC} \rightarrow \mathrm{Y}$ (Hong Kong) \\
\hline Altinay \& Karagol (2005) & 1950-2005 & GCDL & Real GDP and Electricity Consumption & N.A & $\mathrm{EC} \rightarrow \mathrm{Y}$ (Turkey) \\
\hline Yusaf \& Latif (2007) & 1980-2006 & MJL, GC & Real GDP and Electricity Consumption & Yes & $\mathrm{EC} \leftrightarrow \mathrm{Y}($ Malaysia $)$ \\
\hline Yuan et al. (2007) & 1978-2004 & JML, VECM & Real GDP and Electricity Consumption & Yes & $\mathrm{EC} \rightarrow \mathrm{Y}($ China $)$ \\
\hline Mozumder \& Marathe (2007) & 1971-1999 & JML, VECM & $\begin{array}{l}\text { Real GDP per Capita, Electricity Consump- } \\
\text { tion per Capita }\end{array}$ & Yes & $\mathrm{EC} \leftarrow \mathrm{Y}($ Bangladesh $)$ \\
\hline Narayan \& Singh (2007) & 1971-2002 & ARDL, VECM & $\begin{array}{l}\text { Real GDP, Electricity Consumption and La- } \\
\text { bor }\end{array}$ & Yes & $\mathrm{EC} \rightarrow \mathrm{Y}$ (Fiji Islands) \\
\hline $\begin{array}{l}\text { Zachariadis \& Pashourtidou } \\
(2007)\end{array}$ & $1960-2004$ & $\begin{array}{l}\text { JML, } \\
\text { VARGFEVD }\end{array}$ & $\begin{array}{l}\text { Real Income per Capita, Electricity Con- } \\
\text { sumption, prices and weather }\end{array}$ & Yes & $\mathrm{EC} \leftrightarrow \mathrm{Y}($ Cyprus $)$ \\
\hline Tang (2008) & $1972-2003$ & ARDL, TYDL & $\begin{array}{l}\text { Gross National Product and Electricity Con- } \\
\text { sumption }\end{array}$ & No & $\mathrm{EC} \leftrightarrow \mathrm{Y}($ Malaysia $)$ \\
\hline Aktas \& Yilmaz (2008) & 1970-2004 & JML, VECM & $\begin{array}{l}\text { Gross National Product and Electricity Con- } \\
\text { sumption }\end{array}$ & No & $\mathrm{EC} \leftrightarrow \mathrm{Y}($ Turkey) \\
\hline
\end{tabular}


Table 1: Summary of Literature on Relationship between Electricity Consumption and Economic Growth (continuação)

\begin{tabular}{|c|c|c|c|c|c|}
\hline Authors & Time Period & Methodology & Variables & Cointegration & Findings (country studied) \\
\hline \multicolumn{6}{|c|}{ Single-Country Studies } \\
\hline Abosedra et al. (2009) & 1995-2005 & MJL, GC, VARGFEVD & $\begin{array}{l}\text { Real GDP, Electricity Consumption, Real Im- } \\
\text { ports, Temperature and humidity }\end{array}$ & No & $\mathrm{EC} \rightarrow \mathrm{Y}($ Lebanon $)$ \\
\hline Odhiambo $(2009 a)$ & $1971-2006$ & JML, VECM & $\begin{array}{l}\text { Real GDP per Capita and Electricity Con- } \\
\text { sumption per Capita, Employment }\end{array}$ & Yes & $\mathrm{EC} \leftrightarrow \mathrm{Y}$ (South Africa) \\
\hline Odhiambo $(2009 b)$ & 1971-2006 & ARDL, VECM & $\begin{array}{l}\text { Real GDP per Capita and Electricity Con- } \\
\text { sumption per Capita }\end{array}$ & Yes & $\mathrm{EC} \rightarrow \mathrm{Y}($ Tanzania $)$ \\
\hline Lean \& Smyth (2010) & 1971-2006 & TYDL & $\begin{array}{l}\text { Real GDP, Electricity Consumption, Exports, } \\
\text { Capita and Labor }\end{array}$ & Yes & EC $\leftrightarrow \mathrm{Y}$ (Malaysia) \\
\hline Ciarreta \& Zarraga (2010) & $1971-2005$ & TYDL & Real GDP and Electricity Consumption & N.A & $\mathrm{EC} \leftarrow \mathrm{Y}($ Spain $)$ \\
\hline Lorde et al. (2010) & $1960-2004$ & JML, VECM & $\begin{array}{l}\text { Real GDP, Electricity Consumption, Capital, } \\
\text { Labor and Technology }\end{array}$ & Yes & $\mathrm{EC} \leftrightarrow \mathrm{Y}($ Barbados $)$ \\
\hline Acaravici (2010) & $1968-2005$ & JML, VECM & Real GDP and Electricity Consumption & Existed & $\mathrm{EC} \rightarrow \mathrm{Y}$ (Turkey) \\
\hline Chandran et al. (2010) & $1971-2003$ & ARDL, VECM & $\begin{array}{l}\text { Electricity consumption, Real GDP and } \\
\text { Prices }\end{array}$ & Yes & $\mathrm{EC} \rightarrow \mathrm{Y}($ Malaysia $)$ \\
\hline Jamil \& Ahmad (2010) & $1960-2008$ & $\begin{array}{l}\text { JML, } \\
\text { VARGFEVD }\end{array}$ & $\begin{array}{l}\text { Industrial Production, Electricity Consump- } \\
\text { tion and Electricity Prices }\end{array}$ & Yes & $\mathrm{EC} \leftrightarrow \mathrm{Y}($ Pakistan $)$ \\
\hline Ouédraogo (2010) & $1968-2003$ & ARDL, VECM & $\begin{array}{l}\text { Real GDP, Electricity Consumption and Cap- } \\
\text { ital Formation }\end{array}$ & Yes & $\mathrm{EC} \leftrightarrow \mathrm{Y}($ Burkina Faso $)$ \\
\hline Tiwari (2010) & 1971-2006 & JJ, GC- TYDL & Electricity consumption and Employment & NA & $\mathrm{EC} \leftrightarrow \mathrm{Y}$ (India) \\
\hline Shahbaz et al. (2011) & $1971-2009$ & ARDL, GC-VECM & $\begin{array}{l}\text { Electricity consumption, economic growth, } \\
\text { and employment }\end{array}$ & Yes & $\mathrm{EC} \leftrightarrow \mathrm{Y}($ Portugal $)$ \\
\hline Tiwari $(2011 a)$ & 1971-2007 & JJ, GC-VAR & $\begin{array}{l}\text { Real GDP per capita, Electricity consump- } \\
\text { tion, CO2 emissions, Labor and Capital }\end{array}$ & No & $\mathrm{EC} \leftrightarrow \mathrm{Y}($ India $)$ \\
\hline Tiwari $(2011 b)$ & $1970-2007$ & VAR, GC-DL & $\begin{array}{l}\text { Primary energy consumption, } \mathrm{CO} 2 \text { emis- } \\
\text { sions, and economic growth }\end{array}$ & No & $\mathrm{EC} \leftarrow \mathrm{Y}($ India $)$ \\
\hline Tiwari (2012) & $1970-2005$ & $\begin{array}{l}\text { Saikkonen and Lütke- } \\
\text { pohl's approach, GC- } \\
\text { VAR }\end{array}$ & $\begin{array}{l}\mathrm{CO} 2 \text { emissions, energy consumption and } \\
\text { economic growth }\end{array}$ & No & $\mathrm{EC} \leftrightarrow \mathrm{Y}($ India $)$ \\
\hline
\end{tabular}


vation policy may or may not be adopted, depending on the direction of causality. Unidirectional causality running from GDP to energy consumption (EC) implies that income is the initial receptor of exogenous shocks and that equilibrium is restored through adjustment in EC. These are less energy dependent economies and energy conservation policies may be implemented without adverse effects on economic growth and employment. On the other hand, if causality runs from EC to GDP, it implies that the economy is energy dependent and EC measures may stimulate economic growth. Bidirectional causality indicates that both EC and a high level of economic activity mutually stimulate each other. Finally, no-causality between EC and economic growth referred as "neutrality hypothesis", implies that energy conservation measures may be pursued without affecting the economy.

For the analysis, we obtain data of primary energy consumption and electricity consumption from the US Energy Information Administration (June 2011 Monthly Energy Review) with monthly observations. Data of real GDP is obtained from http: / / www . bea. doc .gov/ with annual observations. In order to match the observations, GDP data is interpolated using a linear interpolation method, however, results are unaffected significantly if cubic interpolation is used. Our study period is January, 1973 to December, 2008. ${ }^{2}$

Analysing time series in frequency domain i.e., spectral analysis, could be helpful in supplementing the information obtained by time-domain analysis (Granger 1969, Priestley 1981). Spectral analysis highlights the cyclical properties of data. In our study, we follow the bivariate GC test over the spectrum proposed by Lemmens et al. (2008). They have reconsidered the original framework proposed by Pierce (1979), and proposed a testing procedure for Pierce's spectral GC measure. This GC test in the frequency domain relies on a modified version of the coefficient of coherence, which they estimate in a nonparametric fashion and for which they derive the distributional properties.

Let $E_{t}$ and $Y_{t}$ be two stationary time series of length $T$ representing Energy/ Electricity consumption and Output/GDP respectively. The goal is to test whether $E_{t}$ Granger cause $Y_{t}$ at a given frequency $\lambda$. Pierce's measure for GC (Pierce 1979) in the frequency domain is performed on the univariate innovations series, $\mu_{t}$ and $v_{t}$, derived from filtering the $E_{t}$ and $Y_{t}$ as univariate ARMA processes, i.e.

$$
\begin{aligned}
& \Theta^{E}(L) E_{t}=C^{E}+\Phi^{E}(L) \zeta_{t} \\
& \Theta^{y}(L) Y_{t}=C^{y}+\Phi^{y}(L) \xi_{t}
\end{aligned}
$$

\footnotetext{
${ }^{2}$ Here, we want to make clear that we have preferred to interpolate GDP instead of using industrial production data of which sufficient observations are available because first, interpolation of the data does not destroy the true property of the data (exceptin some cases when an economy experiences abrupt changes frequently); second, industrial production is used in many studies as a proxy for GDP, however, it is not truly representative of the economies, particularly developed ones where a major contributor in GDP is the service sector. Finally we have relied on the results obtained from the linear interpolation method as this method, while changing the frequency to a higher one, maintains the sum, average or final value over each period of the levels which is not the case with other methods such as Cubic interpolation. This interpolation was done in SAS software using "proc expand" command and keeping "observed=average" values and for cubic interpolation we used "proc expand" with "method=spline(natural)". For details, one can refer to SAS procedures.
} 
where $\Theta^{E}(L)$ and $\Theta^{y}(L)$ are autoregressive polynomials, $\Phi^{E}(L)$ and $\Phi^{y}(L)$ are moving average polynomials and $C^{E}$ and $C^{y}$ potential deterministic components. The obtained innovation series $\zeta^{t}$ and $\xi^{t}$, which are white-noise processes with zero mean, possibly correlated with each other at different leads and lags. The innovation series $\zeta^{t}$ and $\xi^{t}$, are the series of importance in the GC test proposed by Lemmens et al. (2008).

Let $S_{\zeta}(\lambda)$ and $S_{\xi}(\lambda)$ be the spectral density functions, or spectra, of $\zeta^{t}$ and $\xi^{t}$ at frequency $\left.\lambda \in\right] 0, \pi[$, defined by

$$
\begin{aligned}
S_{\zeta}(\lambda) & =\frac{1}{2 \pi} \sum_{k=\infty}^{\infty} \gamma_{\zeta}(k) e^{-i \lambda k} \\
S_{\xi}(\lambda) & =\frac{1}{2 \pi} \sum_{k=\infty}^{\infty} \gamma_{\xi}(k) e^{-i \lambda k}
\end{aligned}
$$

where $\gamma_{\zeta}(k)=\operatorname{Cov}\left(\zeta_{t}, \zeta_{t-k}\right)$ and $\gamma_{\xi}(k)=\operatorname{Cov}\left(\xi_{t}, \xi_{t-k}\right)$ represent the autocovariances of $\zeta_{t}$ and $\xi_{t}$ at lag $k$. The idea of the spectral representation is that each time series may be decomposed into a sum of uncorrelated components, each related to a particular frequency $\lambda .^{3}$ The spectrum can be interpreted as a decomposition of the series variance by frequency. The portion of variance of the series occurring between any two frequencies is given by area under the spectrum between those two frequencies. In other words, the area under $S_{\zeta}(\lambda)$ and $S_{\xi}(\lambda)$, between any two frequencies $\lambda$ and $\lambda+d \lambda$, gives the portion of variance of $\zeta_{t}$ and $\xi_{t}$ respectively, due to cyclical components in the frequency band $(\lambda, \lambda+d \lambda)$.

The cross spectrum represents the cross covariogram of two series in frequency domain. It allows determining the relationship between two time series as a function of frequency. Let $S_{\zeta \xi}(\lambda)$ be the cross spectrum between $\zeta_{t}$ and $\xi_{t}$ series. The cross spectrum is a complex number, defined as,

$$
\begin{array}{r}
S_{\zeta \xi}(\lambda)=C_{\zeta \xi}(\lambda)+i Q_{\zeta \xi}(\lambda) \\
\\
\frac{1}{2 \pi} \sum_{k-\infty}^{\infty} \gamma_{\zeta \xi}(k) e^{-\lambda k}
\end{array}
$$

where $C_{\zeta \xi}(\lambda)$ is called cospectrum and $Q_{\zeta \xi}(\lambda)$ is called quadrature spectrum are respectively, the real and imaginary parts of the cross-spectrum and $i=$ $\sqrt{-1}$. Here $\gamma_{\zeta \xi}(k)=\operatorname{Cov}\left(\zeta_{t}, \xi_{t-k}\right)$ represents the cross-covariance of $\zeta_{t}$ and $\xi_{t}$ at lag $k$. The cospectrum $Q_{\zeta \xi}(\lambda)$ between two series $\zeta_{t}$ and $\xi_{t}$ at frequency $\lambda$ can be interpreted as the covariance between two series $\zeta_{t}$ and $\xi_{t}$ that is attributable to cycles with frequency $\lambda$. The quadrature spectrum looks for evidence of out-of-phase cycles (see Hamilton 1994, pp.274). The cross-spectrum can be estimated non-parametrically by,

$$
\hat{S}_{\zeta \xi}(\lambda)=\frac{1}{2 \pi}\left\{\sum_{k=-M}^{M} w_{k} \hat{\gamma} \zeta \xi(k) e^{-i \lambda k}\right\}
$$

\footnotetext{
${ }^{3}$ The frequencies $\lambda_{1}, \lambda_{2}, \ldots, \lambda_{N}$ are specified as follows: $\lambda_{1}=2 \pi / T, \lambda_{2}=4 \pi / T, \ldots$. The highest frequency considered is $\lambda_{N}=2 N \pi / T$; where $N \equiv T / 2$, if $T$ is an even number and $N \equiv(T-1) / 2$, if $T$ is an odd number (see Hamilton 1994, pp.159).
} 
with $\hat{\gamma}_{\zeta \xi}=C \hat{O} V\left(\zeta_{t}, \xi_{t-k}\right)$ the empirical cross-covariances, and with window weights $w_{k}$, for $k=-M, \ldots, M$. Equation (6) is called the weighted covariance estimator, and the weights $w_{k}$ are selected as, the Bartlett weighting scheme i.e. $1-|k| / M$. The constant $\mathrm{M}$ determines the maximum lag order considered. The spectra of Equation (3) and (4) are estimated in a similar way. This crossspectrum allows us to compute the coefficient of coherence $h_{\zeta \xi}(\lambda)$ defined as,

$$
h_{\zeta \xi}(\lambda)=\frac{\left|S_{\zeta \xi}(\lambda)\right|}{\sqrt{S_{\zeta}(\lambda) S_{\xi}(\lambda)}}
$$

Coherence can be interpreted as the absolute value of a frequency specific correlation coefficient. The squared coefficient of coherence has an interpretation similar to the R-squared in a regression context. Coherence thus takes values between 0 and 1 . Lemmens et al. (2008) have shown that, under the null hypothesis that $h_{\zeta \xi}(\lambda)=0$, the estimated squared coefficient of coherence at frequency $\lambda$, with $0<\lambda<\pi$ when appropriately rescaled, converges to a chi-squared distribution with 2 degrees of freedom, ${ }^{4}$ denoted by $\chi_{2}^{2}$.

$$
2(n-1) \hat{h}_{\zeta \xi}^{2}(\lambda) \rightarrow^{d} \chi_{2}^{2}
$$

where $\rightarrow^{d}$ stands for convergence in distribution, with $n=T /\left(\sum_{k=-M}^{M} w_{k}^{2}\right)$. The null hypothesis $h_{\zeta \xi}(\lambda)=0$ versus $h_{\zeta \xi}(\lambda)>0$ is then rejected if

$$
\hat{h}_{\zeta \xi}(\lambda)>\sqrt{\frac{\chi_{2,1-\alpha}^{2}}{2(n-1)}}
$$

with $\chi_{2,1-\alpha}^{2}$ being the $1-\alpha$ quantile of the chi-squared distribution with 2 degrees of freedom. The coefficient of coherence in Equation (7) gives a measure of the strength of the linear association between two time series, frequency by frequency, but does not provide any information on the direction of the relationship between two processes. Lemmens et al. (2008) have decomposed the cross-spectrum (Equation 5) into three parts: (i) $S_{\zeta \Leftrightarrow \Rightarrow \xi}$ the instantaneous relationship between $\zeta_{t}$ and $\xi_{t}$; (ii) $S_{\zeta \Rightarrow \xi}$, the directional relationship between $\zeta_{t}$ and lagged values of $\xi_{t}$; and (iii) $S_{\zeta \Rightarrow \xi}$, the directional relationship between $\xi_{t}$ and lagged values of $\zeta_{t}$, i.e.,

$$
\begin{aligned}
S_{\zeta \xi}(\lambda)= & {\left[S_{\zeta \Leftrightarrow \Rightarrow \xi}+S_{\zeta \Rightarrow \xi}+S_{\xi \Rightarrow \zeta}\right] } \\
& \frac{1}{2 \pi}\left[\gamma_{\zeta \xi}(0)+\sum_{k=-\infty}^{-1} \gamma_{\zeta \xi}(k) e^{-i \lambda k}+\sum_{k=1}^{\infty} \gamma_{\zeta \xi}(k) e^{-i \lambda k}\right]
\end{aligned}
$$

The proposed spectral measure of GC is based on the key property that $\zeta_{t}$ does not Granger cause $\xi_{t}$ if and only if $\gamma_{\zeta \xi}(k)=0$ for all $k<0$. The goal is to test the predictive content of $\zeta_{t}$ relative $\xi_{t}$ to which is given by the second part of Equation (10), i.e.

$$
S_{\zeta \Rightarrow \xi}(\lambda)=\frac{1}{2 \pi}\left[\sum_{k=-\infty}^{-1} \gamma_{\zeta \xi}(k) e^{-i \lambda k}\right]
$$

\footnotetext{
${ }^{4}$ For the endpoints $\lambda=0$ and $\lambda=\pi$, one only has one degree of freedom since the imaginary part of the spectral density estimates cancels out.
} 
The Granger coefficient of coherence is then given by,

$$
h_{\zeta \Rightarrow \xi}(\lambda)=\frac{\left\|S_{\zeta \Rightarrow \xi}(\lambda)\right\|}{\sqrt{S_{\zeta}(\lambda) S_{\xi}(\lambda)}}
$$

Therefore, in the absence of GC, $h_{\zeta \Rightarrow \xi}(\lambda)=0$ for every $\lambda$ in $[0, \pi]$. The Granger coefficient of coherence takes values between zero and one, Pierce (1979). Granger coefficient of coherence at frequency $\lambda$ is estimated by

$$
\hat{h}_{\zeta \Rightarrow \xi}(\lambda)=\frac{\left\|\hat{S}_{\zeta \Rightarrow \xi}(\lambda)\right\|}{\sqrt{\hat{S}_{\zeta}(\lambda) \hat{S}_{\xi}(\lambda)}}
$$

with $\hat{S}_{\zeta \Rightarrow \xi}(\lambda)$ as in Equation (6), but with all weights $w_{k}=0$ for $k \geq 0$. The distribution of the estimator of the Granger coefficient of coherence is derived from the distribution of the coefficient of coherence Equation (8). Under the null hypothesis $\hat{h}_{\zeta \Rightarrow \xi}(\lambda)=0$, the distribution of the squared estimated Granger coefficient of coherence at frequency $\lambda$, with $0<\lambda<\pi$ is given by,

$$
2\left(n^{\prime}-1\right) \hat{h}_{\zeta \xi}^{2}(\lambda) \rightarrow^{d} \chi_{2}^{2}
$$

where $n$ is now replaced by $n^{\prime}=T /\left(\sum_{k=-M}^{-1} w_{k}^{2}\right)$. Since the $w_{k} s^{\prime}$, with a positive index $k$, are set equal to zero when computing $\hat{S}_{\zeta \Rightarrow \xi}(\lambda)$, in effect only the $w_{k}$ with negative indices are taken into account. The null hypothesis $\hat{h}_{\zeta \Rightarrow \xi}(\lambda)=0$ versus $\hat{h}_{\zeta \Rightarrow \xi}(\lambda)>0$ is then rejected if

$$
\hat{h}_{\zeta \Rightarrow \xi}(\lambda)>\sqrt{\frac{\chi_{2,1-\alpha}^{2}}{2\left(n^{\prime}-1\right)}}
$$

Afterward, we compute Granger coefficient of coherence given be Equation (13) and test the significance of causality by making use of Equation (15).

\section{Empirical Findings}

First of all, we tested for the stationarity of the variables considered in our study through Phillips \& Perron (1988) (PP) test, Kwiatkowski et al. (1992) KPSS test and Zivot \& Andrews (1992) (ZA) test. ${ }^{5}$ We report results of unit root analysis in Table 2 below.

It is evident from Table 2 that results obtained from PP and KPSS unit root tests are ambiguous, hence we relied upon $\mathrm{ZA}$ unit root test as this test takes into account, structural break in the data series. In the literature it has been well documented that the unit root test that do not take into account the structural breaks are potentially misleading. Our results of ZA test show that all variables are stationary in the level form i.e., they are integrated of order zero, $I(0)$. Therefore, to proceed with, we used the log level form of the variables. Further, to analyze GC between primary energy consumption and GDP

\footnotetext{
${ }^{5}$ Time series plot and descriptive statisics of the variables are presented in Figure A.1 and Table A.1 respectively, in Appendix. Table A.1 of appendix indicates that all the three variables do not have log normal distribution and therefore, provides scope for our nonlinear analysis. Results of unit root analysis are not presented for space consideration however, it can be obtained from the author upon request.
} 
Table 2: PP, KPSS and ZA Unit Root Estimation

\begin{tabular}{|c|c|c|c|c|c|c|}
\hline \multicolumn{7}{|c|}{ Unit root test: Constant and Linear Trend } \\
\hline \multirow{2}{*}{ Variables } & \multicolumn{2}{|c|}{ PP test } & \multicolumn{2}{|c|}{ KPSS test } & \multicolumn{2}{|l|}{ ZA test } \\
\hline & t-statistic & Bandwidth & t-statistic $\mathrm{I}$ & Bandwidth & t-statistic & \\
\hline $\operatorname{Ln}(\mathrm{EC})$ & $-11.1901^{* * *}$ & 223 & $0.71280^{* * *}$ & 4 & $-7.45844^{* * *} \quad(2001 \mathrm{M} 01)$ & 4 \\
\hline $\operatorname{Ln}(\mathrm{PEC})$ & $-9.644338^{* * *}$ & 8 & $0.39281^{* * *}$ & 7 & $-11.6150^{* * *} \quad(1981 \mathrm{M} 02)$ & 7 \\
\hline $\operatorname{Ln}(\mathrm{GDP} 1)$ & -2.600382 & 16 & 0.083132 & 16 & $-2.429232^{* * *}(1998 \mathrm{M} 03)$ & 16 \\
\hline $\operatorname{Ln}(\mathrm{GDP} 2)$ & -1.930318 & 16 & 0.090097 & 16 & $-2.973513^{* * *}(2002 \mathrm{M} 04)$ & 15 \\
\hline \multicolumn{7}{|c|}{$\begin{array}{l}{ }^{1} \text { GDP1 is obtained using a linear interpolation method and GDP2 is obtained using a } \\
\text { cubic interpolation. }\end{array}$} \\
\hline \multicolumn{7}{|c|}{$\begin{array}{l}2 \mathrm{ZA} \text { test-critical values at } 1 \%, 5 \% \text { and } 10 \% \text { significance level respectively are }-5.57,-5.08 \text {, } \\
\text { and }-4.82 \text { for model when breaks occur in intercept and trend both. }\end{array}$} \\
\hline \multicolumn{7}{|c|}{$\begin{array}{l}{ }^{3} \text { KPSS test-critical values are }-0.216,0.146 \text { and } 0.119 \text { respectively for } 1 \%, 5 \% \text { and } 10 \% \\
\text { level of significance. }\end{array}$} \\
\hline \multicolumn{7}{|c|}{$\begin{array}{l}{ }^{4} \mathrm{PP} \text { test-critical values are }-3.979493,-3.420283 \text { and }-3.132811 \text { respectively for } 1 \%, 5 \% \\
\text { and } 10 \% \text { level of significance level. }\end{array}$} \\
\hline
\end{tabular}

and electricity consumption and GDP we filtered all variables using ARMA models in order to obtain the innovation series. We have used lag length ${ }^{6}$ $M=\sqrt{T}$. The frequency $(\lambda)$ on the horizontal axis can be translated into a cycle or periodicity of $T$ months by $T=2 \pi / \lambda$; where $T$ is the period. Since, we have interpolated GDP annual data to the monthly frequencies, we compared the results of two different interpolation methods to show that whether our interpolation approach matters in drawing conclusion or not.

Figure 1, which presents the result of Granger coefficient of coherence for causality running from GDP (in panel A and B) to primary energy consumption, shows that at 5\% level of significance, GDP Granger-cause primary energy consumption at level of frequencies reflecting long-term, medium-term as well as short-term business cycles. Further, both panel i.e., Panel A and panel B show that Granger-coefficient of coherence which is calculated at different frequencies is higher (and relatively much higher in panel A) to the critical value indicating that there is high strength of Granger-causality running from GDP to primary energy consumption. Therefore, we found that our interpolation procedure has only affected the strength of Granger-causality not the direction and our overall conclusion.

Similarly, Figure 2, which presents the result of Granger coefficient of coherence for causality running from primary energy consumption to GDP (in panel $\mathrm{A}$ and $\mathrm{B}$ ), shows that at 5\% level of significance, primary energy consumption Granger-causes GDP at all the levels of frequencies reflecting shortrun, medium-run and long-run cycles. Similar to Figure 1, Figure 2 also reports that Granger-coefficient of coherence at different frequencies is higher (and relatively much higher in panel A) to the critical value indicating that there is high strength of Granger-causality running from primary energy consumption to GDP. Here we note two points: a) as we move for higher frequencies we find that value of Granger-coefficient of coherence shows in general tendency to move up (of course this upward movement has cyclical movement; b) at very low level of frequency (or in the very long run) i.e., between $0-0.2$ in panel $B$, we do not find evidence that primary energy consumption

\footnotetext{
${ }^{6}$ Diebold (2001, pp.136) we take $M$ equal to the square root of number of observations $T$.
} 
A

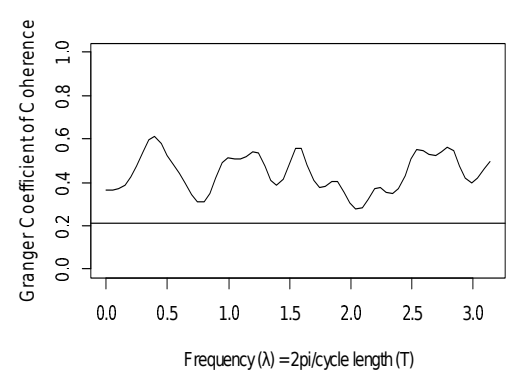

B

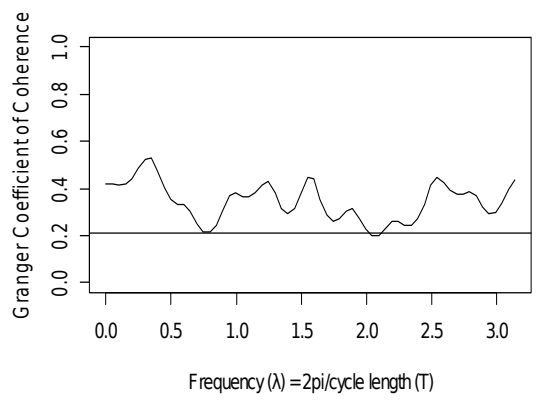

Figure 1: Granger causality from GDP to primary energy consumption. The line parallel to the frequency axis represents the critical value for the null hypothesis, at the $5 \%$ level of significance

Granger-causes GDP.

A

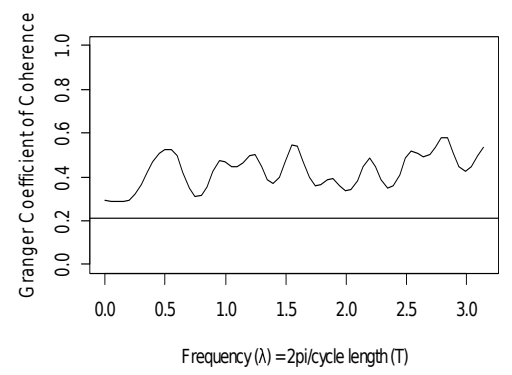

B

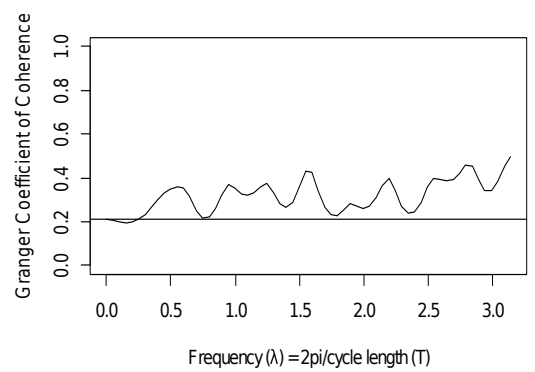

Figure 2: Granger causality from primary energy consumption to GDP. The line parallel to the frequency axis represents the critical value for the null hypothesis, at the $5 \%$ level of significance

Figure 3, which presents the result of Granger coefficient of coherence for causality running from GDP (in panel A and B) to electricity consumption, shows that at 5\% level of significance, GDP Granger-cause electricity consumption at all level of frequencies reflecting long-term, medium-term as well as short-term business cycles. However, here we observe on difference in the diagrammatic results reported in panel A and panel B of Figure 3. In panel A we observe a clear evidence that GDP Granger-cause electricity consumption and in panel $\mathrm{B}$ we find that in the very short range of medium frequencies (i.e., between 1.6-1.8) we do not find that GDP Granger-causes electricity consumption. Therefore, we found that our interpolation procedure in this case only has affected the strength as well as evidence of Granger-causality.

Figure 4 presents the result of Granger coefficient of coherence for causality running from electricity consumption to GDP (in panel A and panel B), shows that at $5 \%$ level of significance, electricity consumption Granger-causes GDP at all frequencies. This reflects that electricity consumption Grangercauses GDP over the short-term, medium-term as well as long-term business 

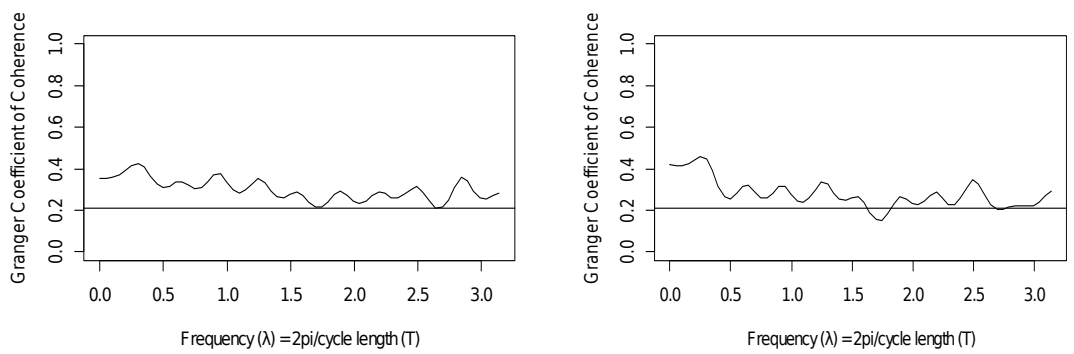

Figure 3: Granger causality from GDP to electricity consumption. The line parallel to the frequency axis represents the critical value for the null hypothesis, at the $5 \%$ level of significance

cycles. In this case too, as with the previous cases, we find that chosen method employed for the interpolation of GDP has little impact on the strength of the Granger-causality.

A

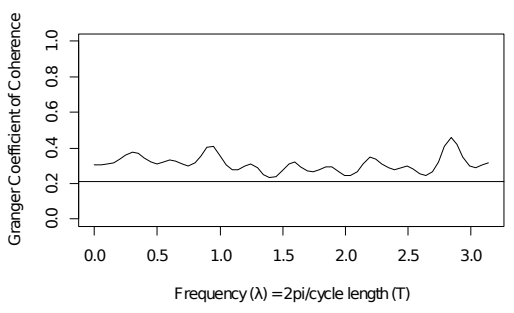

B

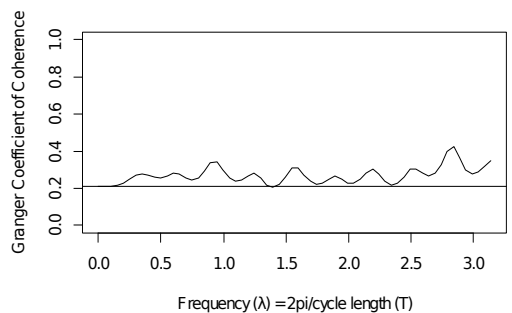

Figure 4: Granger causality from electricity consumption to GDP. The line parallel to the frequency axis represents the critical value for the null hypothesis, at the $5 \%$ level of significance

\section{Conclusions}

In the present study we analyzed GC from primary energy consumption and electricity consumption to GDP for the US by using monthly data covering the period of January, 1973 to December, 2009.

Our results show, for the US economy, that causal and reverse causal relations and its strength between energy consumption and real GDP and electricity consumption and real GDP vary across frequencies. Specifically, our results reveal that primary energy consumption and real GDP both Grangercauses each other in all the frequencies. Hence, we show that both primary energy consumption and high level of economic activity mutually persuade each other over the short-term, the medium-term and the long-term. With respect to the results of GC in the frequency domain between electricity consumption and real GDP are similar to those obtained for the GC between real GDP and primary energy consumption. Hence, we find that energy consump- 
tion (measured either as primary energy or electricity consumption) and real GDP Granger-causes each other at low, intermediate and higher frequencies and thus provide support for the feedback hypothesis. Therefore, energy consumption (in general) and real GDP serve as complements to each other. In one hand energy conservation-oriented policies may have a detrimental impact of economic growth of the US, on the other to attain higher economic growth path may amplify the energy consumption. Thus, while formulating the policies related to energy and economic growth, the the US government, should keep the bidirectional causal evidence in mind. This is particularly because the feedback relationship between energy consumption and economic growth increases the effect of energy conservation on economic growth. Say, for example, when in the first place energy conservation policy is adopted then it will lead to the reduction of economic growth and then low level of economic growth causes the lower level of energy consumption and again economic growth decreases. Therefore, the US economy should not follow energy conservation policy for total economy since it causes two opposite effects on the economy. However, the suggestive point is that the causal relationships between energy consumption and economic growth may be changed at the disaggregated level. Hence, while optimal energy policy may need conservation of energy consumption for some sectors or energy kinds, there may be no need for energy conservation policy for the others and thus optimal portfolio can be obtained in the utilization of various energy sectors or energy kinds.

The unique contribution of the present study lies in decomposing the causality on the basis of time horizons and demonstrating bidirectional shortterm, medium-term and long-term causality between the GDP and energy consumption, in general. We have also been able to demonstrate the cyclical nature of the causal relationship between our test variables. Finally, our study has also contributed by showing the strength of the Granger-causality.

\section{Bibliography}

Abosedra, S., Dah, A. \& Ghosh, S. (2009), 'Electricity consumption and economic growth, the case of lebanon', Applied Energy 86, 429-432.

Acaravici, A. (2010), 'Structural breaks, electricity consumption and economic growth: evidence from turkey', Journal for Economic Forecasting 2, 140-154.

Aktas, C. \& Yilmaz, V. (2008), 'Causality between electricity consumption and economic growth in turkey', ZKÜ Sosyal Bilimler Dergisi 4, 45-54.

Altinay, G. \& Karagol, E. (2005), 'Electricity consumption and economic growth: evidence from turkey', Energy Economics 27, 849-856.

Aqeel, A. \& Butt, S. (2001), 'The relationship between energy consumption and economic growth in pakistan', Asia Pacific Development Journal 8, 101110.

Breitung, J. \& Candelon, B. (2006), 'Testing for short and long-run causality: A frequency domain approach', Journal of Econometrics 132, 363-378.

Chandran, V. G. R., Sharma, S. \& Madhavan, K. (2010), 'Electricity consumption-growth nexus: the case of malaysia', Energy Policy 38, 606-612. 
Ciarreta, A. \& Zarraga, A. (2010), 'Electricity consumption and economic growth in spain', Applied Economics Letters 14, 1417-1421.

Diebold, F. X. (2001), Elements of Forecasting, Vol. 2nd Ed., Ohio: SouthWestern.

Ghosh, S. (2002), 'Electricity consumption and economic growth in india', Energy Policy 30, 125-129.

Granger, C. W. J. (1969), 'Investigation causal relations by econometric models and cross-spectral methods', Econometrica 37, 424-438.

Hamilton, J. D. (1994), Time Series Analysis, Princeton University Press.

Ho, C. \& Siu, K. (2006), 'A dynamic equilibrium of electricity consumption and gdp in hong kong: an empirical investigation', Energy Policy 35, 25072513.

Jamil, F. \& Ahmad, E. (2010), 'The relationship between electricity consumption, electricity prices and gdp in pakistan', Energy Policy 38, 6016-6025.

Jumbe, C. B. L. (2004), 'Cointegration and causality between electricity consumption and gdp: empirical evidence from malawi', Energy Economics 26, 61-68.

Kraft, J. \& Kraft, A. (1978), 'On the relationship between energy and gnp', Journal of Energy and Development 3, 401-403.

Kwiatkowski, D., Phillips, P. C. B., Schmidt, P. \& Shin, Y. (1992), 'Testing the null hypothesis of stationarity against the alternative of a unit root', Journal of Econometrics 54, 159-178.

Lean, H. H. \& Smyth, R. (2010), 'Multivariate granger causality between electricity generation, exports, prices and gdp in malaysia', Energy 35, 36403648 .

Lee, C. C. \& Chang, C. P. . (2005), 'Structural breaks, energy consumption, and economic growth revisited: evidence from taiwan', Energy Economics $27,857-872$.

Lemmens, A., Croux, C. \& Dekimpe, M. G. (2008), 'Measuring and testing granger causality over the spectrum: an application to european production expectation surveys', International Journal of Forecasting 24, 414-431.

Lorde, T., Waithe, K. \& Francis, B. (2010), 'The importance of electrical energy for economic growth in barbados', Energy Economics 32, 1411-1420.

Mozumder, P. \& Marathe, A. (2007), 'Causality relationship between electricity consumption and gdp in bangladesh', Energy Policy 35, 395-402.

Narayan, P. K. \& Singh, B. (2007), 'The electricity consumption and gdp nexus for the fiji islands', Energy Economics 29, 1141-1150.

Narayan, P. K. \& Smyth, R. (2005), 'Electricity consumption, employment and real income in australia: evidence from multivariate granger causality tests', Energy Policy 33, 1109-1116. 
Odhiambo, N. M. (2009a), 'Electricity consumption and economic growth in south africa: a trivariate causality test', Energy Economics 31, 635-340.

Odhiambo, N. M. (2009b), 'Energy consumption and economic growth nexus in tanzania: an ardl bounds testing approach', Energy Policy 37, 617-622.

Ouédraogo, M. (2010), 'Electricity consumption and economic growth in burkina faso: a cointegration analysis', Energy Economics 3, 524-531.

Phillips, P. \& Perron, P. (1988), 'Testing for a unit root in time series regression', Biometrica 75, 335-346.

Pierce, D. A. (1979), 'R-squared measures for time series', Journal of the American Statistical Association 74, 901-910.

Priestley, M. B. (1981), Spectral Analysis and Time Series, London Academic Press.

Shahbaz, M., Tang, C. F. \& Shabbir, M. S. (2011), 'Electricity consumption and economic growth nexus in portugal using cointegration and causality approaches', Energy Policy (in press).

Shiu, A. \& Lam, L. P. (2004), 'Electricity consumption and economic growth in china', Energy Policy 30, 47-54.

Soytas, U., Sari, R. \& Ewing, B. T. (2007), 'Energy consumption, income and carbon emissions in the united states', Ecological Economics 62, 482-489.

Tang, C. F. (2008), 'A re-examination of the relationship between electricity consumption and economic growth in malaysia', Energy Policy 36, 30773085.

Tiwari, A. K. (2010), 'On the dynamics of energy consumption and employment in public and private sector', Australian Journal of Basic and Applied Sciences 4(12), 6525-6533.

Tiwari, A. K. (2011a), 'Energy consumption, co2 emission and economic growth: a revisit of the evidence from india', Applied Econometrics and International Development 11(2), 165-189.

Tiwari, A. K. (2011b), 'Primary energy consumption, co2 emissions and economic growth: Evidence from india', South East European Journal of Economics and Business 6(2), 99-117.

Tiwari, A. K. (2012), 'On the dynamics of energy consumption, co2 emissions and economic growth: Evidence from india', Indian Economic Review 47(1), 57-87.

Yang, H. Y. (2000), 'A note of the causal relationship between energy and gdp in taiwan', Energy Economics 22, 309-317.

Yoo, S. H. (2005), 'Electricity consumption and economic growth: evidence from korea', Energy Policy 33, 1627-1632.

Yoo, S. H. \& Kim, Y. (2006), 'Electricity generation and economic growth in indonesia', Energy 31, 2890-2899. 
Yuan, J., Zhao, C., Yu, S. \& Hu, Z. (2007), 'Electricity consumption and economic growth in china: cointegration and co-feature analysis', Energy Economics 6, 1179-1191.

Yusaf, M. \& Latif, A. (2007), 'Causality between electricity consumption and economic growth in malaysia: Policy implications'.

URL: http://www.energyseec.com/econometrcis_en.asp

Zachariadis, T. \& Pashourtidou, N. (2007), 'An empirical analysis of electricity consumption in cyprus', Energy Economics 29, 183-198.

Zivot, E. \& Andrews, D. (1992), 'Further evidence on the great crash, the oilprice shock, and the unit-root hypothesis', Journal of Business and Economic Statistics 10, 251-270. 


\section{Appendix A}

Table A.1: Descriptive statistics

\begin{tabular}{lcccc}
\hline & $\operatorname{Ln}(\mathrm{EC})$ & $\operatorname{Ln}(\mathrm{PEC})$ & $\operatorname{Ln}(\mathrm{GDP} 1)$ & $\operatorname{Ln}(\mathrm{GDP} 2)$ \\
\hline Mean & 5.419443 & 8.872031 & 8.995869 & 9.008425 \\
Median & 5.451600 & 8.877170 & 8.990502 & 8.991263 \\
Maximum & 5.953059 & 9.154431 & 9.498666 & 9.498123 \\
Minimum & 4.877949 & 8.601188 & 8.481248 & 8.487356 \\
Std. Dev. & 0.274354 & 0.131572 & 0.318821 & 0.318021 \\
Skewness & -0.151128 & -0.029806 & 0.007425 & -0.015713 \\
Kurtosis & 1.876665 & 1.970762 & 1.737696 & 1.731145 \\
Jarque-Bera (Probability) & 24.35831 & 19.13191 & 28.68538 & 28.99763 \\
Sum & $(0.000005)$ & $(0.000070)$ & $(0.000001)$ & $(0.000001)$ \\
Sum Sq. Dev. & 2341.200 & 3832.717 & 3886.215 & 3891.640 \\
\hline Observations & 32.44141 & 7.461121 & 43.80976 & 43.59022 \\
\hline
\end{tabular}

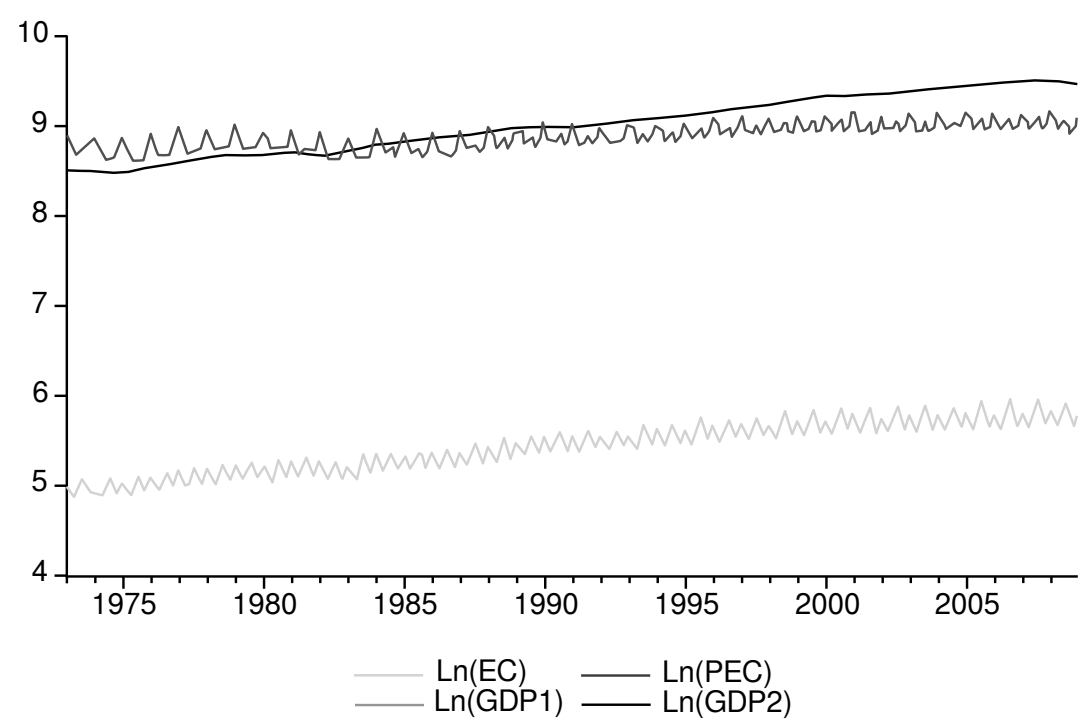

Figure A.1: Time series plots of the variables in logarithms form 